\title{
RAMOS SUCRE Y LA CRÍTICA
}

POR

SALVADOR TENREIRo

Para los poetas venezolanos contemporáneos -y particularmente, para aquéllos que pertenecieron a las promociones surgidas entre 1960 y 1980 - la obra de José Antonio Ramos Sucre constituye la más alta expresión de nuestra literatura. Es - para decirlo con las palabras de Ives Bonnefoy - la lámpara secreta que arde bajo los gestos de nuestra poesía. Desde Trizas de papel (1921), libro genéricamente heterogéneo - primer título de su breve y espléndida bibliografia - hasta El cielo de esmalte, que apareció en 1929, pocos meses antes de su trágica muerte, su obra entera es un ejemplo de lucidez y de rigor poco comunes entre nosotros. Frente a la retórica desfachatez del sonsonete postmodernista, su poesía es pulcritud, austeridad inigualable, que por momentos alcanza la exasperada exactitud de un decir poético que en Leopardi fue exaltada elegancia y que en Gerbasi será, pocos años más tarde, exquisita serenidad.

En lo esencial, la obra de Ramos Sucre se (con)centra en sus poemas en prosa, desconcertantes hasta en su musicalidad. ${ }^{1}$ La suya es una lengua de sonoridades y de ritmos arcanos. Su poesía no está en ningún verso, porque - tal vez por extravagancia de poeta- no escribió que se sepa, ni uno solo, y porque, además, la poesía no está en el verso. Son los versos los que, algunas veces, están en el poema.

Toda su escritura pareciera regida por la idea de acertar —como él sugería— "con el secreto de los prodigios". Sus claves, sin embargo, no han sido establecidas, todavía, en toda su magnitud. No se trata, simplemente - como tanto se ha repetido en los últimos años- de seleccionar "adjetivos insólitos", es decir aquéllos que poseen uno o más rasgos de impertinencia semántica —como dicen—con relación al sustantivo al cual modifican

\footnotetext{
${ }^{1}$ Considerada en toda su amplitud, la obra de Ramos Sucre comprende los 393 textos que integran el volumen Obra completa publicado en Caracas en 1980 por la Biblioteca Ayacucho: 88 pertenecientes a La torre de timón (1925), entre los cuales hay breves ensayos, semblanzas "patrióticas" y reflexiones sobre historia, arte y literatura, y poemas en prosas, que formaron parte del libro Trizas de papel (1921), el ensayo Sobre las huellas de Humboldt, que circulo en 1923, y poemas en prosa no incluidos en Trizas: 126 textos recogidos en Las formas del fuego y 132 de $E l$ cielo de esmalte publicados ambos en 1929. A ello se agregan otras piezas de índole diversa cartas, traducciones, poemas - recopilados por Rafael Ángel Insausti en Los aires del presagio (1960), y una breve compilación de inéditos que Caupolicán Ovalles publicó en 1970.
} 
(tipo "luz execrada"). Los prodigios de los que habla el poeta no están tan-al-alcance-de1a-mano. En todo caso, el secreto de estos prodigios comprendería toda la cadena sintagmática, todo el engranaje verbal (no sólo las relaciones del tipo sustantivo-adjetivo, sino también las de verbo-complemento(s) o las sujeto-predicado). En el poema "El capricornio", se dice que "unas aves de pupila de fuego, metamorfosis de unos lobos empedernidos, alteraban la oscuridad secreta". Eliminados los adjetivos, los complementos determinativos y la frase apositiva, quedará el prodigio: "unas aves ... alteraban la oscuridad".

De manera irregular, fragmentaria y esporádica, la crítica ha dado cuenta de la obra ramosucreana desde la aparición de sus primeras publicaciones. Hay, por ejemplo, unas reseñas magníficas, reveladoras, escritas en su mayoría por poetas que advirtieron la importancia de esa novedosa escritura. Destacan, entre otros, los nombres de José Tadeo Arreaza Calatrava y de Fernando Paz Castillo. El primero, en nota publicada en el diario El Universal, del 20 de agosto de 1922, destaca coma elementos sobresalientes en la escritura de este poeta "que desdeña la rima", el ascetismo de su docta prosa y la originalidad de sus imágenes:

imágenes nuevas ... sin las rarezas y extravagancias del rebuscamiento, esmaltan estas breves y sentidas prosas, bellas como poemas extranjeros que hubieran pasado, con toda la prístima pureza y la gracia nativa, a sonora y robusta forma castellana. ${ }^{2}$

En los primeros años que siguieron a la publicación de sus libros, su nombre -como a veces se repite injustamente- no pasó inadvertido. Publicaba con frecuencia en los periódicos de la época, ante el asombro - es cierto — de muchos de sus contemporáneos. Su obra fue abordada por entonces de muy diversas maneras. Se han documentado notas críticas que abarcan un espectro muy amplio: desde aquéllas que se solazan en comentarios impresionistas, hasta las que indagan en su supuesta misoginia. Los juicios que, en relación a su escritura, prevalecieron durante largo tiempo son aquéllos que intentaron elaborar en torno suyo una especie de fisiología de la creación, en la que se subraya, por ejemplo, el "doloroso desligamiento con lo real". Los términos utilizados por Pedro Sotillo, en 1929, para describir a Ramos Sucre, coinciden asombrosamente con los del mito del poeta solitario, individualista, acético, febril, doliente, oscuro, hermético. ${ }^{3}$ Las implicaciones que directa o indirectamente alcanzan esos adjetivos en la percepción que del poeta se tuvo por mucho tiempo en el país, obliga a considerarlas de suma importancia. (Conviene recordar el desmentido del poeta, en carta a José Nucete Sardi del 7 de enero de 1930: advierte [a Pedro Sotillo] "que se equivoca al calificarme de misógeno".) Sotillo se atrevió, inclusive, a establecer las "causas de oscuridad en los poemas del solitario de La torre de timón", que eran ¡tres!: la particular sensibilidad del autor, su amplia cultura, y la

\footnotetext{
${ }^{2}$ El poeta José Tadeo Arreaza Calatrava tiene el mérito de ser el autor de la primera nota crítica que se publicó en el país sobre la obra de Ramos Sucre. La localización del artículo —cuyo título es "Un libro y un temperamento" - se debe al profesor Basilio Tejedor. Véase Revista Imagen 100-43 (Caracas, julio 1988) 16-17.

3 "Sobre el cumanés José A Ramos Sucre", Cultura Venezolana, 99 (Caracas, noviembre-diciembre 1929) 308-13.
} 
excepcional utilización de una técnica de escritura fundamentada en otorgar a la palabra un "honesto significado originario". Los calificativos de "elitesco", "ininteligible" y hasta "molesto", van a proliferar en algunas otras notas que la crítica le dedica por entonces.

Casi todos estos comentarios coinciden en la superficialidad de un discurso impresionista, saturado de profecías que nunca se cumplen en el poema, y de metáforas clínicas de anecdotario obre la vida del poeta. Ramos Sucre mismo advirtió sobre la ligereza de esas opiniones:

Los juicios acerca de mis dos libros han sido muy superficiales. No es fácil escribir: un buen juicio sobre dos libros tan acendrados o refinados. Se requieren en el crítico los conocimientos que yo atesoré en el antro de mis dolores. Y no todo el mundo ha tenido una vida $\tan$ excepcional. ${ }^{4}$

Las piedras mágicas, primer libro dedicado íntegramente a examinar la obra de Ramos Sucre, aparece publicado en 1945, quince años después de su fallecimiento. Su autor, el poeta Carlos Augusto León, reune algunos testimonios personales (había sido su alumno en el Liceo Caracas) alrededor de los cuales va construyendo una imagen del poeta muy cercana, por cierto, a la creada con anterioridad por algunos de los autores señalados en líneas precedentes. Su ensayo se propone, sin embargo, ceñirse lo más estrictamente posible al análisis de la obra, y es en ese intento donde alcanza su más alto nivel. Todas sus interpretaciones parten, no obstante, de la premisa de que toda la obra es fundamentalmente autobiográfica, de que todas sus "personas poéticas" son una sola, fragmentaciones del yo diseminados en la historia del discurso. En la diversidad espacio-temporal a la que remiten sus poemas (la Grecia de la Antigüedad Clásica, el medioevo hispánico o la Italia renacentista, por ejemplo), Carlos Augusto León destaca la obsesión del poeta por evadir la realidad: "A diario, a cada instante - escribe - recurría el poema huyendo del tormento ... La historia fue para él escala de evasión. Se dio a evocar tiempo y paisajes lejanos para escapar a la tremenda realidad".

Unos de los ejes temáticos de la obra ramosucreana, a la los que presta mayor atención en su análisis, es el que identifica con el título "sufrimiento y muerte", que va verificando en las diversas escenas donde tienen lugar muertes trágicas, mutilaciones de órganos y múltiples padecimientos físicos. Examina también varios aspectos de la poética ramosucreana, que sintetiza en los conceptos de condensación (de síntesis para usar su mismo término) de adjetivación y de singularidad de su discurso poético: "Sus poemas en prosa, redondos, cerrados en sí mismos, de un simbolismo alto y cernido, tienen muchas veces el valor de piedras preciosas ... brillantes, pulidos en sus facetas diversas, concretos en su forma, de claro reflejo". El libro de Carlos Augusto León favoreció, como ningún otro, el acceso a Ramos Sucre. Fue durante muchos años uno de los escasos textos con que se contaba para ello, y el único que se presiente escrito con admiración, con pasión fervorosa en homenaje a su poesía.

Casi tres décadas tuvieron que transcurrir para que la obra de Ramos Sucre alcanzara el lugar de privilegio que le correspondía. Las más jóvenes promociones literarias de

\footnotetext{
${ }^{4}$ Carta a Lorenzo Ramos Sucre (Caracas, 25 de octubre de 1929).
} 
entonces, empeñadas en renovar la literatura del país, advirtieron la importancia de esa escritura que en lugar de endurecerse con el peso de los años adquiría una elasticidad inigualable. La publicación de sus Obras, en 1956, en la colección de la Biblioteca Popular Venezolana, editada por el Ministro de Educación, favoreció su difusión por todo el país. Félix Armando Núñez, el prologista, subraya la "extraña poesía en prosa de original vivencia y forma exacta. Pesadilla cambiante en que las imágenes oníricas se presentan con la nitidez y la coherencia de una vigilia a menudo infernal". Núñez alude, también, influenciado probablemente por las observaciones de Paz Castillo sobre la obra ramosucreana, al carácter plástico de muchas de sus imágenes: arte de medalla y camafeo, o mejor de primoroso relicario o joyero que sólo deben abrir para su valoración cabal los que estiman la belleza como un don sagrado. ${ }^{5}$

La mayoría de los jóvenes escritores de entonces insistían en la necesidad de rescatarlo para la poesía, razón por la cual se privilegiaba, esencialmente, lo que en su obra se percibía como lo más poético, vale decir Las formas del fuego y El cielo de esmalte. Reivindicarlos para la poesía no era tan sólo un acto de justicia, sino una sanción contra aquéllos que lo habían condenado al olvido. En tal sentido, Francisco Pérez Perdomo señala: "Ramos Sucre ha debido ser visto, sin ninguna duda, como un reto y un desafuero. De allí, era de esperarse, el silencio que se urdió en torno a su nombre. Darle paso hubiera implicado, colateralmente, la ruína de muchos prestigios literarios a la vez que el impulso de un movimiento poético mucho más audaz y menos provinciano".

Reivindicarlo para la poesía era, pues, un grito de guerra que anunciaba una voluntad decidida a transformar las convenciones estéticas de la literatura oficial. El poeta Juan Calzadilla, en 1956, y varios años después Ludovico Silva, han insistido en señalar algunas de las transformaciones que se fueron produciendo en la poesía venezolana. Una de ellas tiene que ver con la adopción, como forma expresiva, del poema en prosa, cuyo ejemplo más elocuente es - en opinión de Ludovico Silva - el libro Los cuadernos del destierro de Rafael Cadenas. "Se volvió - escribe- a leer a Rimbaud y a los surrealistas y se asimiló en nuestro país de una vez por todas el espíritu de la lírica moderna, corresponde a Ramos Sucre, de este modo, un sitial como gran adelantado ... lo que había hecho no era otra cosa que incorporar la poesía venezolana a la modernidad". ${ }^{6}$

Las nuevas lecturas que se le dedican se inscriben en corrientes distintas del pensamiento crítico. Unas ponen el acento en el examen de su sintaxis y de su proceso fabulador, otras intentan establecer las claves simbólicas de su universo poético. Se subraya la riqueza y precisión de su discurso, sus ejes temporales, el uso del yo elocutivo, el valor de sus adjetivaciones. La supresión del que (y de otros relacionantes y subordinantes sintácticos) ya no se la califica de obsesión maniática, sino que se interpreta como condensación de un discurso que apuesta por la pureza verbal. La oscuridad de su poesía, considerada anteriormente como vicio artepurista, se constituye ahora en uno de los fundamentos de su poética. Se revisan sus afinidades con otros escritores y con otras obras, y para sustentar la modernidad de su discurso, se comparan algunos de sus textos con otros de Mallarmé, de Robert Browning y de Jorge Luis Borges.

\footnotetext{
${ }^{5}$ Prólogo a las Obras de José Antonio Ramos Sucre. (Caracas, M.E., 1956) 17.

6 "Ramos Sucre y nosotros", Revista Nacional de Cultura 219 (Caracas , marzo-abril 1975).
} 
Entre los textos críticos más relevantes que, en torno a la obra ramosucreana, se han publicado en los últimos años, destacan los de Ángel Rama, Gustavo Luis Carrera y Guillermo Sucre. El libro de Rama, El universo simbólico de José Antonio Ramos Sucre, es uno de los pocos, si no el único, que privilegia por encima de todo lo publicado por el poeta, La torre de Timón. Una de las razones de esta elección, posiblemente la de mayor importancia, se debe a que con ese libro culmina - contrariamente a lo que siempre se dijo al respecto- el proceso creador del poeta, puesto que con él se abre un período que continuará en la misma línea discursiva que aquí se inició con éxito. La torre de Timón es el producto de una "cuidadosa reorganización" de dos publicaciones anteriores a las que se permite suponer en el poeta, como señala Rama, "una voluntad estructural nítida, una concepción del libro como un orden significativo, que lo convierte en una suma de poesía y pensamiento". Por ello resulta un libro tan especial dentro del proceso creador ramosucreano, pues revela, con mayor nitidez que los otros, el esfuerzo por "ceñir la imaginación más exultante al rigor de un pensamiento implacable, por adecuar el sueño a los designios de la vigilia".

Uno de los aspectos estudiados por Ángel Rama es el referido al "discurso intelectual". Al examinar, en tal sentido, el ensayo que el poeta había dedicado a Alejandro de Humboldt, el sabio y naturalista alemán, encuentra algunos de los puntos más relevantes de la poética ramosucreana:

Tanto por su formación intelectual como por su trato con las manifestaciones de un arte construído merced a un espeso tejido simbólico, Ramos Sucre creyó que el campo del artista no estaba exclusivamente en una expresión "bella" también en una expresión "sabia". Parte del hermetismo caracteriza sus textos de allí nace, y la red de símbolos y debe analizarse directamente sobre esos textos aparencialmente oscuros.

En el análisis de los textos que se inician con el Yo, Rama distingue dos tipos de narración: una ulterior, en la cual el yo refiere, desde el presente, acciones pasadas, lo que permite alargar la distancia del yo con lo narrado, y otra simultánea que Rama llamará "contemplativa" (utilizando el término implícito en el título de uno de los poemas) en la cual se observa una congelación del tiempo. Este yo "expectrante" irá inmovilizándolo todo, cristalizando la historia y alejándola del instante a partir del cual se narra. De esta manera "la precisión de la prosa de Ramos Sucre funciona como un sistema de petrificación". Otro de los rasgos del yo - la dominante militar de sus disfraces, escribirá Rama- es la frecuencia con que aparece en calidad de héroe solitario y cruel, que adquiriría valor simbólico si se le remitiese a la historia del país.

Gustavo Luis Carrera ha estudiado la importancia del símbolo en tanto procedimiento que contribuye a vincular la obra de Ramos Sucre al romanticismo, y de manera particular, a la figura de Goethe. Para ello parte del ensayo que Tzvetan Todorov dedica a las relaciones entre el símbolo y la estética romántica en Théories du Symbole, donde afirma que los supuestos estéticos de ese movimiento se "condensan" en el símbolo. Carrera analiza varios textos del poeta venezolano - algunos teóricos como "Sturm und Drang"- en los que encuentra posiciones ideológicas similares a las de los románticos. En otro texto: "Sobre la poesía elocuente" destaca Carrera el concepto de identidad tal como fue asumido 
por aquéllos: "poesía-símbolo", lo inefable, es decir que el contenido del símbolo va a la indeterminación y a lo mítico de lo indecible y escapa a la razón. Es la vaguedad que lleva a la sobreabundancia de sentidos y al permanente devenir de la concepción romántica de la poesía.

El estudio del símbolo como unidad expresiva es retomado en otro ensayo en el que Gustavo Luis Carrera examina principalmente la oscuridad y el hermetismo de su discurso:

Vemos en la obra de Ramos Sucre tres procesos lúdicos y conceptuales, destinados a distintos niveles de captación de conocimiento y de sensibilidad cómplice. El más ostensible sería el de la identificación del referente. Es el ámbito de la dilatada carga histórica, literaria, estética, autobiográfica, terminológica, que puebla sus textos de nombres, hechos y situaciones que son otras tantas claves potencialmente comprensibles.

Para Guillermo Sucre, uno de los aspectos a destacar es el referido a las "alusiones culturales de su poesía, en tanto que ellas constituyen verdaderas metáforas en las que el conocimiento del mundo se mezcla a las visiones de lo imaginario. Sus poemas no recrean la historia sino que la borran, la vuelven misterio original en un universo nuevo: el que dibujan las palabras. Junto a esas "metamorfosis de la historia y de los textos", señala también la metamorfosis del yo que se fragmenta en varios otros sin que se insinue "sacralización biográfica" alguna. Ramos Sucre no hizo sino ejercer "ese don que, según Baudelaire, tiene el poeta de entrar, a su antojo, en el personaje de cada cual y encarnar su destino". Todos esos monólogos dramáticos - a la manera de Robert Browning, de Pound, de Eliot o de Borges - empleados por el poeta fortalecen la "neutralidad" de su escritura, en cuyo ejercicio se obtiene la "única identidad posible: el vasto teatro de la humanidad".

A través de todo el ensayo se advierte un tono de ironía, al parecer destinada a cuestionar rnuchas de las opiniones que han circulado sobre la obra del poeta. Algunos paréntesis, ciertas frases interrogativas dejan constancia de que el discurso de Guillermo Sucre se constituye como un diálogo - como una respuesta, más bien- a otros discursos críticos que lo precedieron en el tiempo. Así, cuando aborda el aspecto concerniente a la riqueza verbal de la obra, insiste en que ella no reside - $\tan$ sólo- en la "proliferación léxica", en la "veracidad sustitutiva" - como se ha dicho siempre - sino - y fundamentalmenteen la elegancia en "hacer que todo el discurso adquiriera la forma más concisa, aún incisiva, así como el 'entorno' más sutilmente elocuente. La elegancia en Ramos Sucre es adustez: ese último ideal de los seres problemáticos y escépticos". Lo más importante en su obra es la búsqueda, en cuanto tal, de un lenguaje inédito. De este modo, sus imágenes "reúnen lo justo y lo distante: su misterio no excluye la exactitud de la formulación verbal". Lo fundamental en ellas no es el mundo de referencias al cual aluden, sino su propia naturaleza, su disposición a constituirse en imágenes imaginantes, como Guillermo Sucre las define.

\section{El POEMA EN PROSA}

Con la frase "poeta en prosa, y como tal ininteligible", encabezaba Augusto Mijares, en julio de 1930, un artículo suyo sobre la poesía de Ramos Sucre. En ella se evidencia el desconcierto que su escritura produjo entre sus lectores de entonces, a pesar de que ni su 
léxico ni su sintaxis atentan contra la lengua castellana. Lo que resultaba, en realidad, ininteligible era su poesía prosificada, significativa circunstancia en un país donde la concepción del hecho poético, era inseparable del verso. La prosa se definía siempre en negativo. Su estatuto consistía, precisamente, en carecer de poeticidad, pues no tenía ni metro ni ritmo. Sin ellos no podía aspirar a la representación del universo, función reservada a la poesía. En la precisión del verso, el poeta simboliza - como se decía - el orden y la armonía del universo. Pero Ramos Sucre no sólo no escribía en verso, sino que, además, sus poemas en prosa carecían del lirismo, del intimismo característicos, por ejemplo, de la prosa de Chateaubriand, lo cual lo hacía aún más ininteligible.

En verdad, muchos de los pasajes que en cuentos y novelas han sido calificados de poéticos por la tradición, nada tienen que ver con el poema en prosa. Las frases encantadoras y armoniosas, traicionan muy a menudo. La prosa que intenta acercarse a la poesía por medio de artificios métricos y retóricos, con el propósito de crear una ilusión musical versificada, está condenada al fracaso. Cuando Baudelaire, en le Prefacio al Spleen de Paris, sueña con el milagro de una prosa poética, sin ritmo y sin rima, ceñida a los "movimientos líricos del alma", a las "ondulaciones del ensueño" y a los "sobresaltos de la conciencia" no alude tan sólo al verso tradicional, sino también, a las prosas poéticas a la manera de Chateaubriand. A partir de Baudelaire, el poema en prosa moderno será, singularmente distinto, incluso a los magníficos del Gaspard de la nuit.

La total libertad que la prosa ofrecía a la imaginación del poeta, favoreció y estimuló nuevas búsquedas, intentos muchas veces desconcertantes que iban revelando vastísimas regiones que habían permanecido ocultas. La prosa se presta con excelencia a la "traducción de los más extraños estados poéticos". Sin una forma fija a la que recurrir, sin un ritmo codificado de antemano, todo el poema en prosa es creación. "Todo poema en prosa es, simplemente, un poema."

Una de las características a resaltar en la historia del poema en prosa es la referida a sus constantes re-envíos hipotextuales, para utilizar un término grato a Genette. En tres discursos poéticos distintos, como son, por ejemplo, los de Aloysius Bertrand, Baudelaire, y Ramos Sucre, el poema en prosa se constituye, se "injerta" sobre textos anteriores a partir de los cuales se inicia un nuevo recorrido escritural. En algunos casos el re-envío no remite a un texto preexistente sino al paisaje representado en un cuadro, al retrato miniaturizado en una medalla, o a un camafeo. E1 propio autor del Gaspard de la nuit advierte acerca del contenido del libro: "fantasías a la manera de Rembrandt y de Callot". Así mismo en lo que respecta a las obras de Ramos Sucre, Fernando Paz Castillo observa que muchos de sus poemas "son reminiscencias, más que de lecturas, de laminas que ilustran viejos libros": Gustavo Doré, Alberto Durero". ${ }^{8}$

Se trata de una mención, cuya referencia esta constituida por grabados, cuadros, o esculturas. Fidias, Durero y Rubens son nombrados con cierta frecuencia. Esta mención

\footnotetext{
${ }^{7}$ A. Kibédi Varga plantea que en el concepto "poema en prosa", la palabra "poema" está empleada en un sentido moderno, $y$ "prosa" en uno ya superado, que lo remite a una concepción que demanda la separación de géneros opuestos. Les constantes du poème. Analyse du langage poétique 268. ${ }^{8}$ Fernando Paz Castillo, "José Antonio Ramos Sucre, el solitario de la torre de Timón", Ramos Sucre ante la crítica (Caracas: Monte Ávila, 1981) 19.
} 
integra, algunas veces, una expansión nominal encabezada por un relacionante del tipo "a semejanza de" y otras, una expansión cuyo núcleo es un verbo, en copretérito generalmente: "reproducia", "semejaba", "imitaba". En esas comparaciones el relacionante varía constantemente en razón de que Ramos Sucre ha extrañado de su discurso poético subordinantes y relacionantes del tipo "que", "como" y "donde".

\section{EL PALIMPSESTO COMO POEMA}

La complejidad constructiva de su universo referencial es uno de los rasgos más sobresalientes de la escritura de Ramos Sucre. Sus referencias son, como bien ha señalado Guillermo Sucre, metáforas que conducen a un conocimiento diferente, a una "aventura de la imaginación".

La mención no sólo constituye uno de sus rasgos estilísticos, más relevantes, sino que a menudo integra el núcleo estructurante del poema. De ahí que no se trate de una simple alusión a personajes o acontecimientos históricos o literarios. Una de las menciones que seguramente podrá aclarar, en futuros trabajos, innumerables pasajes oscuros de la obra, es la referida a Jean Bodin (1530-1596), filósofo y jurista francés, uno de los fundadores de la teoría política moderna, cuya République debió conocer Ramos Sucre durante sus estudios universitarios. No obstante, la obra de Bodin que seguramente lo impactó fue su Démonomanie des Sorciers. Es poco probable que en Venezuela hubiese circulado algún ejemplar, pero lo que sí puede afirmarse es la existencia, en la biblioteca del poeta, del Dictionnaire infernal de Colin de Plancy, en edición parisina de Henry Plon. Pareciera que buena parte de la Demonomonía bodiniana hubiese sido incorporada. Muchas de las escenas de terror, de las descripciones infernales y de los actos de crueldad que pueblan la obra ramosucreana, recuerdan aquéllas del Diccionario infernal.

Sin embargo, Ramos Sucre no cita, no imita, no parodia ni plagia a los otros: los reescribe. Su escritura es un complejo proceso verbal que utiliza una gran variedad de recursos: condensación, expansión, amplificación, prosificación. Su trabajo consiste en transferir, en transformar, en transmutar. Sus poemas son, muchas veces, expansiones de enunciados pertenecientes a obras diversas. Algunos, como "La cuna de Mazeppa", permiten acceder con relativa facilidad al texto de su referencia: el poema Mazeppa de Les Orientales de Víctor Hugo. ${ }^{9}$ Otros son condensaciones, derivaciones de otras obras, muchas de las cuales pertenecen, en sus lenguas de origen, a géneros literarios distintos que, en el palimpsesto ramosucreano, devienen poemas en prosa.

\footnotetext{
${ }^{9}$ El texto ramosucreano, además de estar escrito en prosa, es mucho más breve que el de Hugo (que alcanza 138 versos). Breve y esencialmente descriptivo. Las imágenes del poema ramosucreano están organizadas alrededor del sujeto. Ramos Sucre reproduce en lo fundamental el poema de Hugo a partir de la decimotercera estrofa. La "estación nueva" y la "humilde flor esporádica" que "supera al yerbazal fecundo, tapiz de la sabana, mullido por la primavera" del poema ramosucreano pudiera considerarse como una expansión del verso: "en la estación de las flores", de Hugo. "Las aves de rapiña que circulan frecuentemente en las alturas del aire" es condensación, en una sola frase, de "pájaros de presa" y de "nube de pájaros". El poema ramosucreano es más plástico, más cromático: el sol diferencia los tonos del verde en las ondulaciones de la pradera agitada por el viento, y una nube proyecta la sombra de su vuelo.
} 
La identidad de cada uno de los sujetos de sus poemas en prosa es muy diversa. El sujeto de cada poema es independiente de los otros. No hay ningún indicio - al menos a nivel de la superficie significante - que asegure la continuidad actancial. Hidalgos, cruzados, novicios. Predestinados, contemplativos, desesperados. En numerosos casos, el título del poema aclara la identidad del sujeto. Aunque sus identidades varíen, muchas de sus funciones los acercan, sin embargo. Por ello, algunos lectores confiesan percibir una especie de tensión episódica que va enlazando algunas secuencias independientes, y a veces distantes. Si alguien intentara, por ejemplo, una lectura temática, podría agrupar, seguramente, muchos de esos sujetos: en períodos históricos (Edad Media, Renacimiento), en actividades desempeñadas (cirujanos, jardineros), en rasgos de personalidad (desesperados, contemplativos), etc.

Entre los rasgos predominantes que los acercan, el de la abyección parece ser uno de los más importantes. Muchos de ellos son sujetos deshechos, aniquilados. Proliferan cadáveres en descomposición que son exhibidos con satisfacción por sus asesinos, mujeres condenadas a cabalgar sobre camellos roídos de sarna. Humores, miasmas pestilenciales atraviesan el texto. Terror, asco, aprobio, vértigo, humillación, náusea. Algunos confiesan amar -como el sujeto de "La vida del maldito"- el dolor, la belleza y la crueldad. El sujeto registra, con morbosa fascinación, los horrores humanos, los actos más viles y abyectos, torturas de un retinamiento extremo. El sujeto de "La tribulación del novicio", sufre, como muchos otros, en soledad, herido por la desolación: "Vivo sintiendo el contacto, de carnes redondas y desnudas ... todos los arreos del sátiro podrían ser míos ... Sufro por mi estado religioso mayor esclavitud que un presidiario". Por medio de un discurso fragmentado en grupos nominales apositivos, el novicio revela sus deseos insatisfechos. En su confesión predomina el presente iterativo, en duración: "vivo en una celda", sufro por mi estado religioso".

A pesar de que las confesiones de muchos de esos sujetos ponen al descubierto sus heridas más íntimas, su discurso no subvierte ningún código, no mutila el cuerpo de la lengua, sino que se ciñe, por el contrario, a sus reglas más estríctas. Ese ardor que no se calma con claustro inaccesible ni con desierto desolado, como expresa uno de ellos, alcanza sosiego en la severidad de una escritura que no conoce desfallecimientos ni flaquezas. En la palabra de quien pone al desnudo su sexualidad más instintiva, no hay ni un solo sonido que excite, que incite a la excitación sexual. Su discurso parece haber confiscado la soberanía de sus pulsiones.

"Los textos - había confesado Ramos Sucre - son el único ardor que exhibo para afuera." Aunque ese ardor textual pudiera constituir un desplazamiento metonímico del ardor sexual, el discurso ramosucreano permanece inalterable, vigilante, imperturbable. El único adorno que se permite a sí mismo es el de la exactitud. Toda exploración retórica y lingüística que emprenda el poeta debe conducir a un discurso de extrema precisión. Su labor consistirá, por lo tanto, en "atinar con el secreto de los prodigios". 
